\title{
Experimental and numerical damping behavior analyses of carbon/ epoxy laminated plates including viscoelastic material
}

\author{
R. Mateu Pastor \& H. Le Sourne \\ ICAM Nantes, France \\ GeM Institute UMR CNRS 6183, France \\ P. Cartraud \\ Ecole Centrale de Nantes and GeM Institute UMR CNRS 6183, France \\ E. Le Gal La Salle \\ ICAM Nantes, France \\ LTeN UMR CNRS 6607, France
}

\begin{abstract}
The research work presented in this paper aimed to optimize the transmittance of a wind turbine carbon/epoxy plane support by including into the laminate one or several frequency-dependent interleaved viscoelastic layers. The objective of the present study was then to optimize the damping characteristics of the support upper-plate with viscoelastic layers while keeping an acceptable bending stiffness. The optimization consisted in creating holes in the viscoelastic layer in order to facilitate the resin through layer penetration during the co-curing manufacturing process. One part of the research consisted in optimizing both the size of the holes and their repartition in the viscoelastic layer. DSC and DMA tests allowed to characterize the stiffness and damping properties of the damped composite plates in a given frequency range and resulting mechanical properties were further used to set a finite element model with the objective to simulate the overall viscoelastic composite plate receptance.
\end{abstract}

\section{INTRODUCTION}

The development of renewable energy is a major challenge for the future. While the fossil resources are diminishing, the worldwide energy demand continues to increase. Today, most of the industrialized countries primarily use energy from nuclear power because it is very economical. However, the nuclear energy produces some radioactive waste that is hazardous for human and nature. Energy transition is one of the biggest challenge of the 21 st century in order to keep the environment cleaner. In this perspective, the team Energy Observer has embarked on a project which is to design and construct a floating laboratory called "Energy Observer" catamaran (Figure 1).

The catamaran is fully working with electrical energy from renewal energy sources which are powered by self-generated hydrogen, sun, and wind. The previous name of the boat was "Formule Tag" which won the race called Jules Verne in 75 days in 1994, and this boat was converted in a shipyard at Saint Malo, which is on the North-West coast of France. In order to use the solar energy, the boat is equipped with $130 \mathrm{~m} 2$ of solar panels and, to

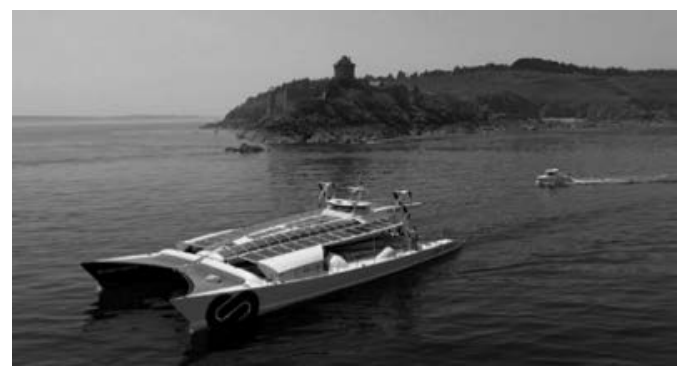

Figure 1. Energy observer vessel.

use the wind power, two vertical axis wind turbines have been installed (Figure 2). These wind turbines are able to create energy regardless of the wind direction. The main purpose of Energy Observer vessel is to explore the oceans without leaving any exhaust gas to the environment.

The research work presented this paper aimed at increase the damping characteristics of the wind turbines support upper-plates to prevent mechanical damage as well as noise disturbance due to vibrations, by working both experimentally and 


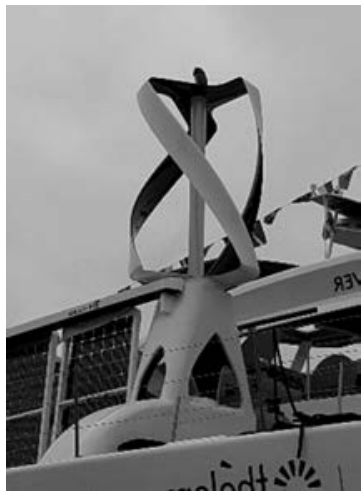

Figure 2. Energy observer wind turbine.

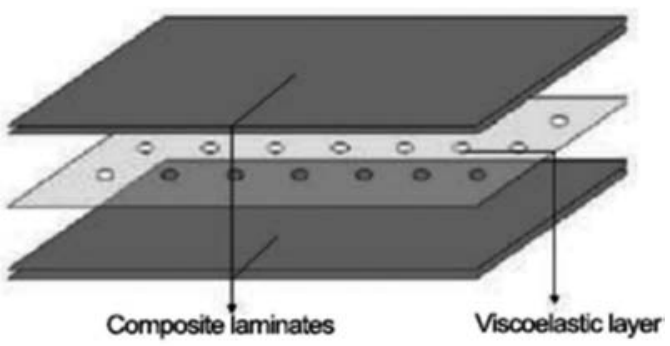

Figure 3. Perforated viscoelastic film constrained between composite laminate plates-Robinson \& Kosmatka (2006).

numerically on a carbon/epoxy laminated plate including frequency-dependent interleaved viscoelastic layers.

Sandwich structures are increasingly used in aeronautic, automotive, naval and offshore industries among others. Such interest in sandwich materials is mainly motivated by their properties as they offer both higher bending rigidity and lower density in comparison with similar metallic structures. One solution consists in inserting one (or several) viscoelastic layer(s) inside the laminate, as shown in Figure 3. The mechanical energy is then dissipated thanks to shear solicitations between composite and viscoelastic layers.

\section{REVIEW OF EXISTING WORK}

Recent research on materials has focused on adding new functionalities to composite structures, mixing for example composite and viscoelastic materials. As a result, such multifunctional composites are nowadays used for specific purpose like damping or reducing acoustic emissions, which were not initially the aim of those materials.
However, adding some damping functionalities has to be realized without affecting too much the main structural properties of the composite, i.e. its density and stiffness.

One of the first works on constrained viscoelastic composite laminates was done in 1959 by Ungar et al. (1959), who studied the influence of several parameters like damping factor, thickness and number of viscoelastic layers constrained between aluminum plates. They found that the number of viscoelastic layers affects the damping at all frequencies.

Well after, Saravanos and Chamis (1991) worked on modeling composite laminates damped by interlaminar viscoelastic layers. Using the so-called discrete layer laminate damping theory to simulate the behavior of such laminates, they compared different arrangements and two kinds of constraining materials: composite and aluminum. They showed that composite plates with strong anisotropy variations have potentially higher damping properties than geometrically equivalent aluminum plates.

Just a few years later, carbon fiber/epoxy composite interleaved with a Polyethylene-co-acrylic acid viscoelastic layer inserted at mid plane was investigated by Liao et al. (1994). Prepreg standard vacuum-bag molding was used to create samples and the evolution of damping factor with fibers direction. However, inserting a viscoelastic layer into a composite laminate may cause both delamination and important loss of bending stiffness. One solution proposed by the authors consisted of perforating the viscoelastic layer(s), allowing matrix polymer to get through resulting holes during the curing process.

Using the vacuum assisted resin transfer molding process, Robinson and Kosmatka (2006) manufactured similar composite plates with the objective to control the damping to stiffness ratio. The authors observed that imposing a contact equal or higher than $95 \%$ increases from 2 to 14 the loss factor but, at the same time, decreases the bending stiffness from 6 to $60 \%$. Moreover, keeping a contact surface equal to $95 \%$, an increase of the hole size and distance between holes allows to increase the plate rigidity.

Pan and Zhang (2009) worked on composite laminates with embedded acrylonitrile butadiene rubber (NBR) layer. They designed five plates with varying the hole size, which affects the percentage of contact between composite and NBR layers. When the perforated area is higher than $7 \%$ of the plate surface, the loss factor remains small and the bending stiffness does vary as compared to similar undamped plate.

The same authors (2009) developed an innovative method to determine the damping of a co-cured T700/TT85 unidirectional prepreg 
composite laminate with embedded NBR viscoelastic layer. From 3-point bending tests performed on co-cured composite laminates as well as tension tests performed on NBR layer, they measured both the loss factor and Young modulus using dynamic mechanical thermal analysis (DMTA). Applying a $1 \mathrm{~Hz}$ constant excitation, they observed that damping factor increases with temperature from $-60^{\circ} \mathrm{C}$ to $-7^{\circ} \mathrm{C}$, then decreases from $-7^{\circ} \mathrm{C}$ to $100^{\circ} \mathrm{C}$, the maximum value occurring during the viscous state. Moreover, the Young modulus was shown to decrease slowly in glassy state, faster in viscous state and slowly again in elastomeric state.

More recently, Hujare and Sahasrabudhe (2014) also showed that inserting viscoelastic materials in a sandwich beam structure allows to increase the damping factor. They compared different viscoelastic materials in medium frequency range and found that nitrile, SBR, urethane and butyl materials better damp vibrations of such beam than PMMA, polyethylene, and polypropylene.

Wan et al. (2016) worked on vibrational and damping characteristics of a multilayered constrained damping plate, using the transfer matrix method to calculate its natural frequencies and loss factor. They also varied the number and thickness of viscoelastic layers as well as the arrangement of the materials. As expected, multilayers structure achieves better damping when the number of viscoelastic layers increases but, from a certain number of layers, the loss factor does not vary significantly anymore. Symmetrical structures offer a better loss factor than other kind of structure.

Xu et al. (2016) presented recently a multi-objective optimization of composite laminates including viscoelastic layers. Using layer-wise finite element method, they were able to maximize modal damping while minimizing at the same time structural mass. Frequency-dependent viscoelastic material properties were considered in their study. As a first step, they considered a symmetrically hybrid composite laminated plate with two interleaved viscoelastic layers inserted in different positions. They observed that these latter offer better damping properties when inserted at mid-plane.

Zhai et al. (2017) optimized the loss factor of a cross-ply composite plate including a viscoelastic layer. Using the Navier solution based on first-order shear deformation theory, they tried to maximize the damping level by varying the plate aspect ratio as well as the ratio between composite and viscoelastic layer thicknesses. They found that a square plate offers the highest loss factor and when the ratio between the plate dimensions and thickness increases, the loss factor decreases.

In the present study, manufacturing, experimental characterization, and parametric numerical study of the dynamic behavior of carbon/epoxy laminate including viscoelastic layers are presented. To characterize damped (with viscoelastic material) and non-damped (without viscoelastic material) laminated plates, static 3-point bending tests as well as dynamic measurement analyses (DMA) were carried out. Different composite plate configurations were investigated, inserting or not viscoelastic layers, making or not holes inside such layers in order to facilitate resin transfer and varying holes/overall plate surface ratio.

Mechanical properties measured were further used to simulate numerically the dynamic response of square composite/viscoelastic plates. Normal mode analyses were firstly performed to extract eigenfrequencies and mode shapes, varying the number of holes in viscoelastic layers. Finally, frequency response analyses were carried out in order to quantify the plate receptance and to analyse the sensitivity of holes distribution on response level attenuation.

\section{COMPOSITE PLATES AND TEST SAMPLES MANUFACTURING}

Prepreg carbon (including or not viscoelastic layers) lay-ups were first built varying fibers orientation $\left(0^{\circ}, 45^{\circ},-45^{\circ}, 90^{\circ}\right.$, etc. $)$ when draping the different plies. Note that extraction of air bubbles was performed every four plies then co-curing of plates was then processed at a temperature of $180^{\circ} \mathrm{C}$.

Each plate sample was manufactured using following materials:

- HexPly ${ }^{\circledR}$ UD pre-preg carbon epoxy M21E/34\%/ UD194

- DYAD $601^{\circledR}$ Soundcoat ${ }^{\mathrm{TM}}$ viscoelastic material (0.5 mm thickness)

Plates samples consist of one layer of DYAD $601^{\circledR}$ constrained between top and bottom Hex$\mathrm{Ply}^{\circledR}$ UD prepreg carbon/epoxy laminates, with the following stacking sequence: $[0,45,-45,90$, DYAD 601, 90, $-45,45,0]$.

Using the same procedure, four different sets of samples with a thickness of $15 \mathrm{~mm}$ were manufactured inserting (or not) a viscoelastic layer inside the laminate and varying diameter and number of holes created in the viscoelastic film:

- The so-called without viscoelastic layer set includes the samples without any viscoelastic material (only carbon/epoxy). It is expected to have the highest stiffness but the lowest damping characteristics.

- The $0 \%$ set groups the samples that include a constrained viscoelastic layer without perforations. It is expected to have the highest loss factor but the lowest stiffness. 
- The $2 \%$ set groups the samples that include a constrained viscoelastic layer with four holes and a diameter of $3 \mathrm{~mm} \mathrm{(2 \%} \mathrm{of} \mathrm{the} \mathrm{sample}$ surface).

- The 5\% set groups the samples that include a constrained viscoelastic layer with four holes and a diameter of $5 \mathrm{~mm}$ ( $5 \%$ of the sample surface).

From the different manufactured plates, static 3-point bending analysis samples were cut respecting European norm ISO 14125. Top and edge views of resulting samples are presented in Figure 5.

\section{EXPERIMENTAL CHARACTERIZATIONS}

As illustrated in Figure 4, static characteristics of manufactured samples were measured from three-point bending quasi-static tests performed on an Instron ${ }^{\mathrm{TM}} 5566 \mathrm{~A}$ bench. For each set listed in Table 1, five $80 \mathrm{~mm}$ long samples were tested, applying at mid-length a deflection varying from 0 to $1.5 \mathrm{~mm}$. The test speed was set to $2 \mathrm{~mm} / \mathrm{min}$, and the Young's Modulus was extracted from the measurement performed in a strain range varying from $0.05 \%$ to $0.25 \%$. Resulting 3-point bending force/displacement curves are depicted in Figure 6 and corresponding bending stiffness are given in

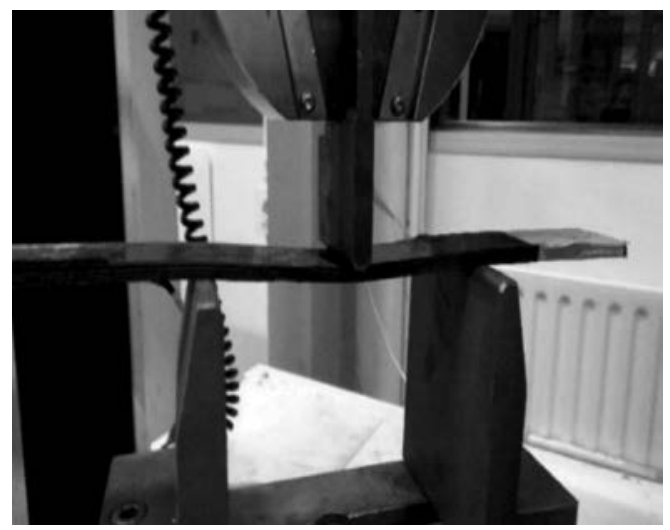

Figure 4. Static 3-point bending test on Instron 5566A bench.

Table 1. Samples characteristics.

\begin{tabular}{lllll}
\hline Sample & w/o visco. & $0 \%$ & $2 \%$ & $5 \%$ \\
\hline Holes diameter D (mm) & $\phi$ & $\phi$ & 3 & 5 \\
Holes number & $\phi$ & $\phi$ & 4 & 4 \\
$\begin{array}{l}\text { Holes surface/Overall } \\
\text { surface }\end{array}$ & $\phi$ & $\phi$ & $2 \%$ & $5 \%$ \\
\hline
\end{tabular}

Table 2. This table shows that inserting a viscoelastic layer leads as expected to a strong decrease of Young modulus. It also appears that creating holes on the viscoelastic layer improves the resin transfer between neighboring carbon layers and allows for increasing up to 4 times the sample bending stiffness.

Only damped samples (sets $0 \%, 2 \%$, and $5 \%$ ) were characterized on Dynamic Mechanical Analysis bench as it appeared that non-damped carbon/epoxy samples were too stiff with respect to available machine exciter. Consequently, in order to compare non-damped samples with viscoelastic damped ones, a damping factor $\tan \delta=0.005$ was chosen from EduPack ${ }^{\mathrm{TM}}$ database for the nondamped carbon/epoxy laminate.

Damped samples dimensions were chosen to comply with DMA tests requirement regarding exciter/sample flexibility ratio. Indeed, coupons

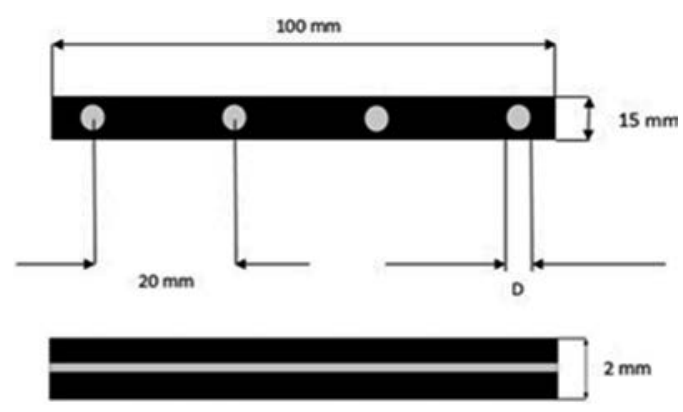

Figure 5. Dimensions of bending test samples.

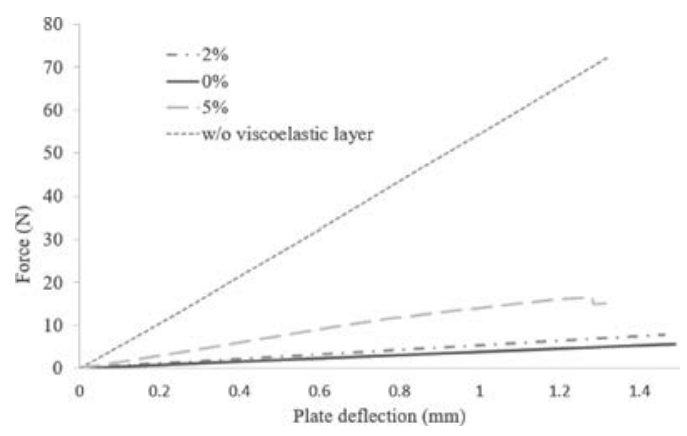

Figure 6. Bending resistance vs deflection curves.

Table 2. Bending stiffness three-point bending.

\begin{tabular}{lllll}
\hline Sample & w/o visco. & $0 \%$ & $2 \%$ & $5 \%$ \\
\hline $\mathrm{K}(\mathrm{N} / \mathrm{m})$ & 241920 & 12019 & 17395 & 48203 \\
$\mathrm{~K}_{\mathrm{w} / \mathrm{o}} / \mathrm{K}_{\mathrm{x} \%}$ & $\phi$ & 20 & 14 & 5 \\
\hline
\end{tabular}


Table 3. Coupons characteristics for DMA tests.

\begin{tabular}{llllllll}
\hline & $\begin{array}{l}\text { Bending } \\
\text { stiffness }\end{array}$ & Density & $\mathrm{fb}$ & $\mathrm{f}$ & $\begin{array}{l}\text { Hole } \\
\text { diameter }\end{array}$ & $\begin{array}{l}\text { Hole } \\
\text { number }\end{array}$ & $\begin{array}{l}\text { Elastic } \\
\text { modulus }\end{array}$ \\
\cline { 2 - 8 } Sample & $(\mathrm{N} / \mathrm{m})$ & $\left(\mathrm{kg} / \mathrm{m}^{3}\right)$ & $(\mathrm{Hz})$ & $(\mathrm{Hz})$ & $(\mathrm{mm})$ & & $(\mathrm{MPa})$ \\
\hline $\begin{array}{l}\text { Without visc. } \\
\text { layer }\end{array}$ & 241920 & 1500 & 4509 & 360 & $\phi$ & $\phi$ & 63000 \\
$0 \%$ & 12019 & 1410 & 1029 & 82 & $\phi$ & $\phi$ & 3130 \\
$2 \%$ & 17395 & 1340 & 1278 & 102 & 3 & 2 & 4530 \\
$5 \%$ & 48203 & 1310 & 2153 & 172 & 5 & 2 & 12553 \\
\hline
\end{tabular}
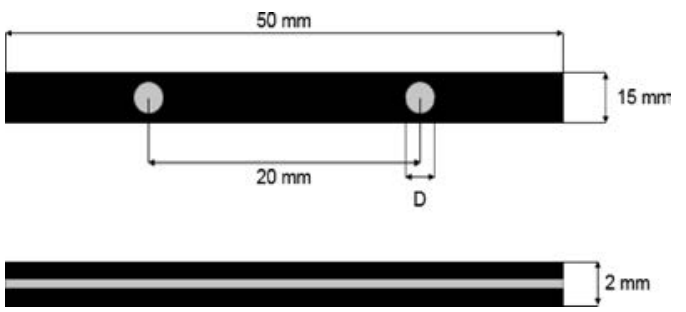

Figure 7. Dimensions of DMA tests samples.

width $b$ and length $L$ were chosen in such a way that both first natural bending frequency and bending stiffness of coupons fulfill the following conditions:

$$
\begin{aligned}
& f_{b}=0,71 \times \frac{b}{L^{2}} \times \sqrt{\frac{\frac{K L^{3}}{48 I}}{\rho}} \\
& K=\frac{48 E I}{L^{3}}<10^{5} \mathrm{~N} / \mathrm{m}
\end{aligned}
$$

where $\rho$ is the constitutive material density and $\mathrm{E}$ the Young's modulus, I the moment of inertia and $\mathrm{K}$ the bending stiffness as given in Table 2.

For DMA tests, coupons were cut from $2 \mathrm{~mm}$ thick plates with following stacking sequence: $[0$, $45,-45,90$, DYAD $601,90,-45,45,0]$. Respecting the aforementioned requirements, coupons length and width were chosen equal to $50 \mathrm{~mm}$ and $15 \mathrm{~mm}$ respectively. Table 3 present the characteristics of the different sets of coupons used for Dynamic Measurement Analyses. In this table, $f_{b}$ and $f$ denote the sample first bending normal mode and the maximum excitation frequency according to Metravib $^{\mathrm{TM}}$ DMA bench instructions, respectively.

As illustrated in Figures 8 and 9, DMA bending tests were performed on Metravib ${ }^{\mathrm{TM}}$ VA2000 bench, which allows for measuring the frequency evolution of stiffness and damping characteristics of the tested material within a range from $0.001 \mathrm{~Hz}$ to $200 \mathrm{~Hz}$.

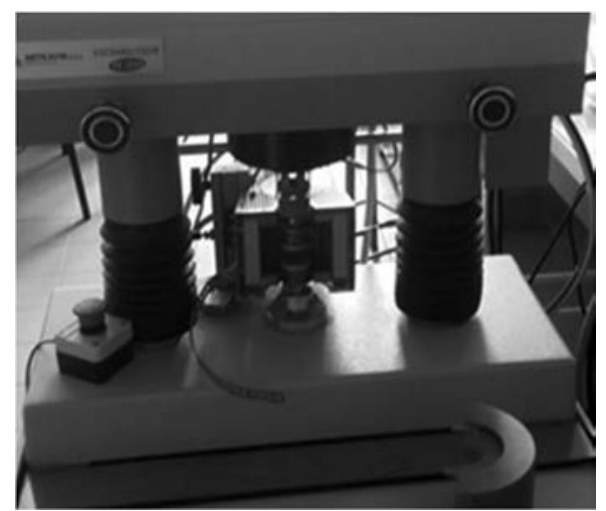

Figure 8. Metravib VA2000 DMA bench.

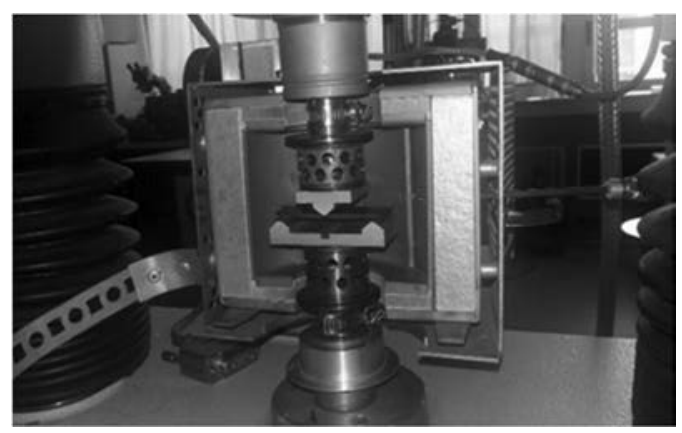

Figure 9. Bending mounting.

DMA experimental parameters were set as follows:

- Initial static deflection amplitude: $1 \mathrm{~mm}$

- Dynamic deflection amplitude: $0.1 \mathrm{~mm}$

-1 to $101 \mathrm{~Hz}$ frequency range with a step of $2 \mathrm{~Hz}$

- Span: $45 \mathrm{~mm}$

- Maximal force $+/-100 \mathrm{~N}$

- Temperature: $24^{\circ} \mathrm{C}$

The frequency evolution of the loss factors extracted from DMA tests for the three different damped laminate sets $(0 \%, 2 \%$ and $5 \%)$ are 
presented in Figure 10. We realized our measures on 5 samples per set. As expected, an increase of the perforated area leads to a decrease of the loss factor, even if this tendency is not clearly highlighted at low frequency range.

In Figure 11, where the damped over nondamped laminate loss factor ratios are compared, it appears that at very low frequency $(1 \mathrm{~Hz})$, adding a viscoelastic layer inside carbon/epoxy laminate allows to increase by a factor of 18 the loss factor. Note also that the loss of damping when creating holes inside the viscoelastic film is not significant at such frequency. On contrary, at $50 \mathrm{~Hz}$ (Figure 12), creating holes inside the viscoelastic film allows to increase by a factor of 52 the loss factor for $0 \%$ set and by up to 44 for $5 \%$ set.

It worth noting that the value given for the DYAD601 viscoelastic material at $1 \mathrm{~Hz}$ has been extracted from Soundcoat ${ }^{\mathrm{TM}}$ DYAD's provider database.

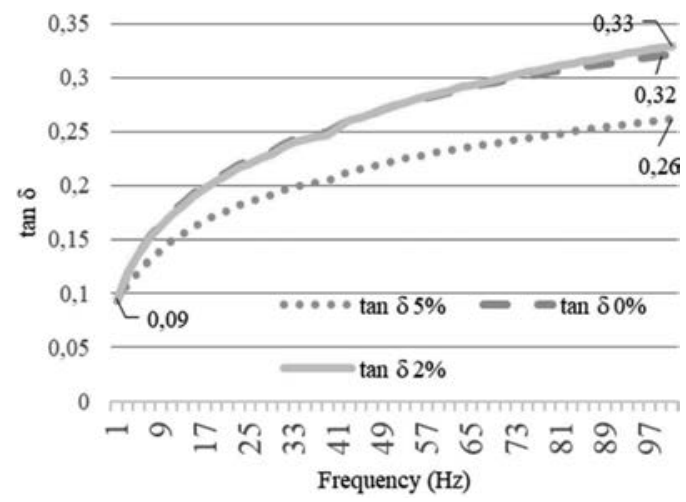

Figure 10. Loss factor vs frequency for sets $0 \%, 2 \%$ and $5 \%$.

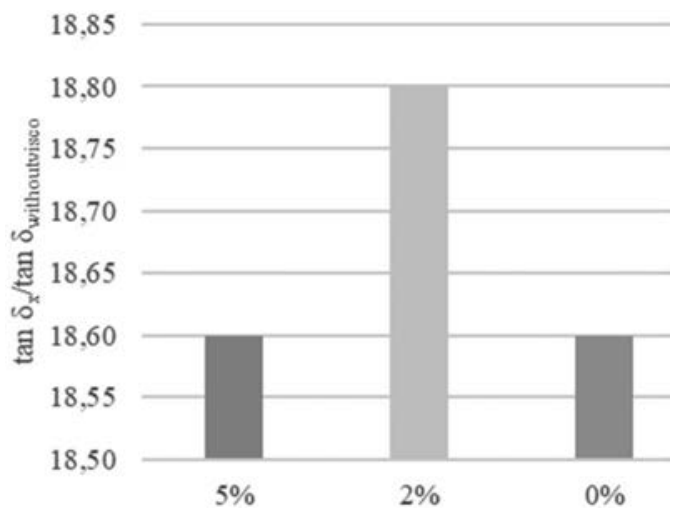

Figure 11. Ratio between damped and non-damped laminate loss factors at $1 \mathrm{~Hz}$.

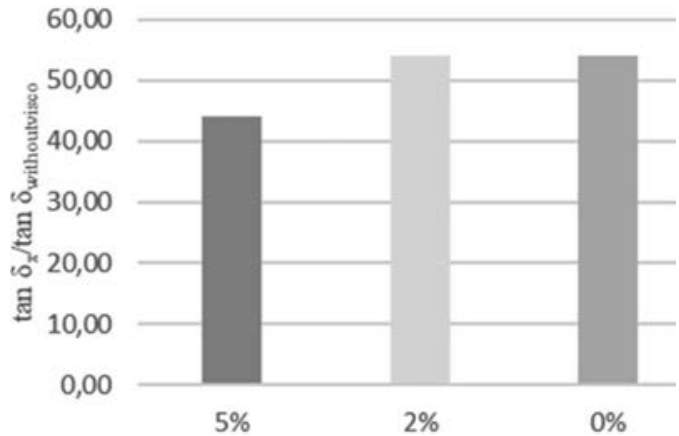

Figure 12. Ratio between damped and non-damped laminate loss factors at $50 \mathrm{~Hz}$.

\section{NUMERICAL ANALYSES}

\subsection{Static analyses}

The support upper-plate can be seen as a superposition of two types of "thick layers", each one corresponding to a laminate. The plates dimensions are $450 \times 450$ and the thicknesses are given in Table 6.

For the numerical analysis, only a quarter of the $7 \%$ damped laminate plate was considered.

Regarding the laminate, characteristics of a unidirectional carbon/epoxy ply extracted from (Tabiei, 2017) are given in Table 4.

Table 5 presents the mechanical characteristics of DYAD given by then manufacturer of this polymer (Soundcoat 2018). For trade secret, DYAD composition is not given by the manufacturer.

We calculated hyperelastic Neo-Hookean coefficient thanks to elastic manufacturer properties.

$$
\begin{array}{ll}
C 10=\frac{\mu}{2} & \mu=G \\
D 1=\frac{\lambda}{2} & \lambda=K-\frac{2}{3} \tilde{G}
\end{array}
$$

where $\mu$ and $\lambda$ are lame coefficient, $K$ the bulk modulus and $\mathrm{G}$ the shear modulus.

The objective of the numerical analysis was mainly to optimize the damping properties of the plate, without decreasing too much its bending stiffness and strength, by finding the best arrangement of holes in the viscoelastic layer. The following stacking sequences were considered for the plate numerical study, and the different plate configurations are presented in Table 6:

Stacking sequences of the considered plate:

$\left[(0,45,-45,90,90,-45,45,0)_{2}\right.$, DYAD601, $(0,45,-$ $\left.45,90,90,-45,45,0)_{2}\right]$ 
Table 4. Material properties of UD carbon/epoxy ply.

\begin{tabular}{lll}
\hline UD Carbon & Value & Units \\
\hline $\mathrm{E}_{11}$ & 126000 & $\mathrm{MPa}$ \\
$\mathrm{E}_{22}$ & 11000 & $\mathrm{MPa}$ \\
$\nu_{12}$ & 0,345 & \\
$\mathrm{G}_{12}$ & 6600 & $\mathrm{MPa}$ \\
$\rho$ & $1.5 \mathrm{E}-9$ & $\mathrm{~T} / \mathrm{mm}^{3}$ \\
\hline
\end{tabular}

Table 5. Material properties of DYAD.

\begin{tabular}{lll}
\hline DYAD601 & Value & Units \\
\hline C10 & 0.4 & $\mathrm{MPa}$ \\
D1 & 0 & $\mathrm{MPa}$ \\
Structural damping & 0.5 & $\mathrm{At} 1 \mathrm{~Hz} / 20^{\circ} \mathrm{C}$ \\
$\rho$ & $1.5 \mathrm{E}-9$ & $\mathrm{~T} / \mathrm{mm}^{3}$ \\
\hline
\end{tabular}

Table 6. Plates particulars.

\begin{tabular}{lllll}
\hline $\begin{array}{l}\text { Hole } \\
\text { number }\end{array}$ & $\begin{array}{l}\text { Holes spacing } \\
(\mathrm{mm})\end{array}$ & $\begin{array}{l}\text { Holes Diam. } \\
(\mathrm{mm})\end{array}$ & $\mathrm{h}_{\text {dyad }}$ & $\mathrm{h}_{\text {carbon }}$ \\
\hline 0 & $\phi$ & 48 & 1.5 & 6.75 \\
4 & 75 & 34 & 1.5 & 6.75 \\
8 & 75 & 24 & 1.5 & 6.75 \\
16 & 45 & 17 & 1.5 & 6.75 \\
36 & 32 & 12 & 1.5 & 6.75 \\
64 & 25 & 8 & 1.5 & 6.75 \\
$\begin{array}{l}\text { Only carbon } / \\
\text { epoxy }\end{array}$ & $\phi$ & & 0 & 7.5 \\
\hline
\end{tabular}

where $h_{\text {dyad }}$ and $h_{\text {carbon }}$ represent respectively the midlayer thickness and the top/bot thickness layer.

The finite element model of the wind turbine support plate, built using ABAQUS pre-processor, is presented in Figure 13. The hyperelastic layer is meshed with C3D8RH solid elements taking into account the presence of the holes, while the upper and lower laminates are meshed using S4R shell elements. Holes are filled with carbon/epoxy material and are meshed with C3D8R solid elements. Holes distribution are presented in Figure 13.

Regarding the boundary conditions, the plate is supported along 2 edges and symmetrically constrained in the other 2 faces. As shown in Figure 14, a total force of $1000 \mathrm{~N}$ is distributed on $10000 \mathrm{~mm}^{2}$ surface around the plate center.

Considering above loading case, static finite element analyses were carried out for plates with 0 to 64 holes using ABAQUS implicit solver for the different plates listed in Table 6. Post-processed deflections and strain energy related to viscoelastic DYAD layer are presented in Table 7. As expected,

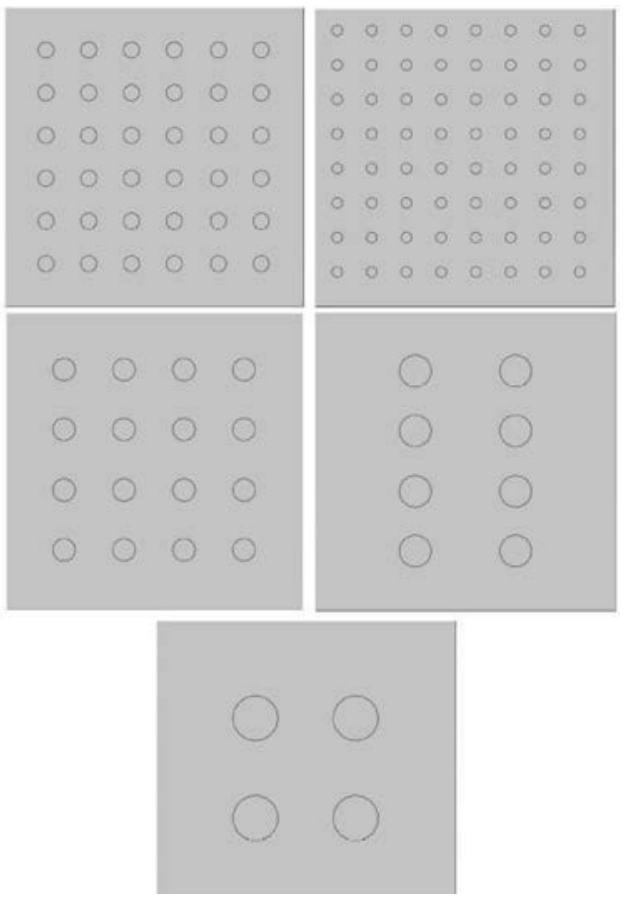

Figure 13. Holes distribution.

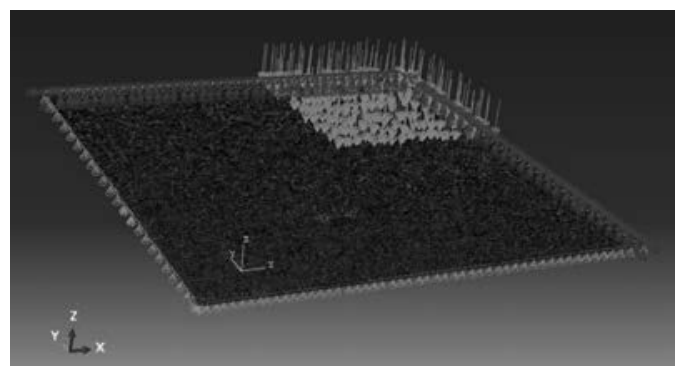

Figure 14. Overall finite element model.

Table 7. Static analysis results.

\begin{tabular}{llll}
\hline $\begin{array}{l}\text { Holes } \\
\text { number }\end{array}$ & $\begin{array}{l}\text { Deflection } \\
(\mathrm{mm})\end{array}$ & $\begin{array}{l}\text { Strain } \\
\text { Energy }(\mathrm{J})\end{array}$ & $\begin{array}{l}\text { Increase/ } \\
\text { undamped }(\%)\end{array}$ \\
\hline 0 & 1.88 & 776 & $394 \%$ \\
2 & 1.01 & 410 & $165 \%$ \\
4 & 0.68 & 276 & $79 \%$ \\
8 & 0.6 & 249 & $58 \%$ \\
16 & 0.52 & 214 & $37 \%$ \\
36 & 0.47 & 194 & $24 \%$ \\
64 & 0.45 & 184 & $18 \%$ \\
Without & 0.38 & 157 & \\
DYAD & & & \\
\hline
\end{tabular}


the plate deflection decreases with the number of holes in the viscoelastic layer. It is also worth noting that deflection and strain energy are increased by up to $394 \%$ when the viscoelastic layer is not perforated. This spread may be reduced down to $18 \%$ with a viscoelastic layer perforated by 64 holes is included into the laminate (Figures 15 and 16).

\subsection{Dynamic analyses}

Based on the same finite element model, modal and frequency response analyses were carried out in order to quantify and compare the receptance of the different configurations. The first natural bending mode of the support upper-plate, such as the one presented in Figure 17, is expected to be mainly excited during the rotation of the wind turbine.

Table 8 lists the related natural frequency obtained for each configuration. As expected, adding progressively holes into the viscoelastic damping layer increases the rigidity of the plate, which leads to an increase of the first bending natural frequency.

The objective of the dynamic numerical analyses being to compare the receptances, vertical excitation amplitudes were arbitrarily chosen equal to $\mathrm{F}_{0}=1000 \mathrm{~N}$. Direct frequency response analyses were then performed, varying the frequency excitation from -50 to $+50 \mathrm{~Hz}$ around the first natural bending frequency.

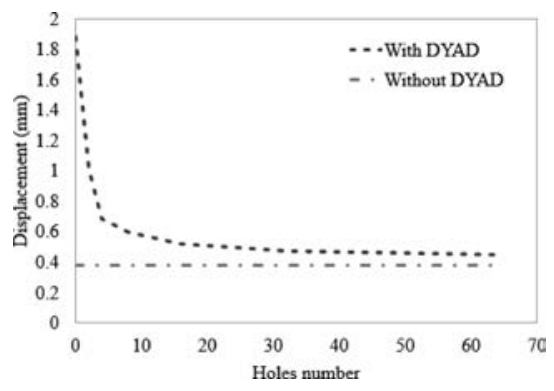

Figure 15. Holes influence on displacement.

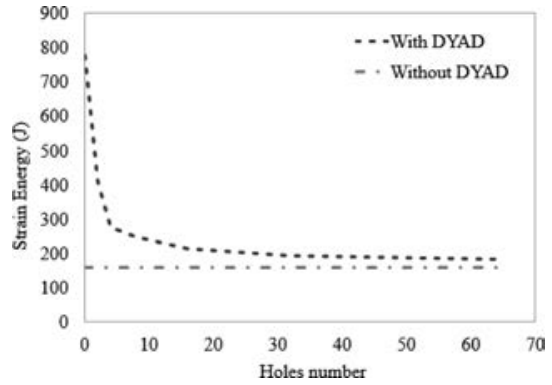

Figure 16. Holes influence on strain energy.

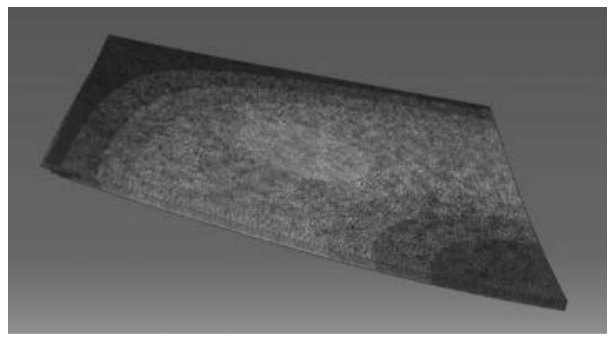

Figure 17. First bending mode.

Table 8. First natural frequency.

\begin{tabular}{ll}
\hline $\mathrm{Nb}$ of holes & 1st Natural freq. (Hz) \\
\hline 0 & 208.2 \\
4 & 342 \\
8 & 361.2 \\
16 & 390.6 \\
36 & 410.2 \\
64 & 428 \\
Without DYAD & 455.7 \\
\hline
\end{tabular}

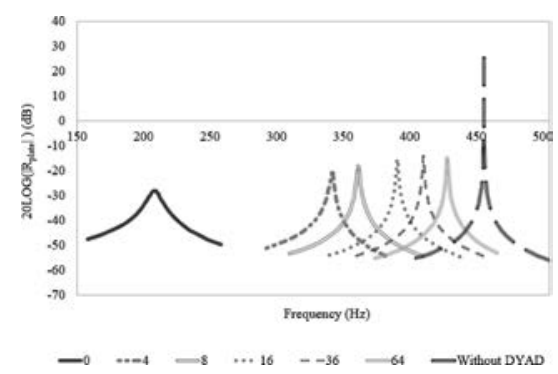

Figure 18. Frequency evolution of the receptance gain for vertical excitation.

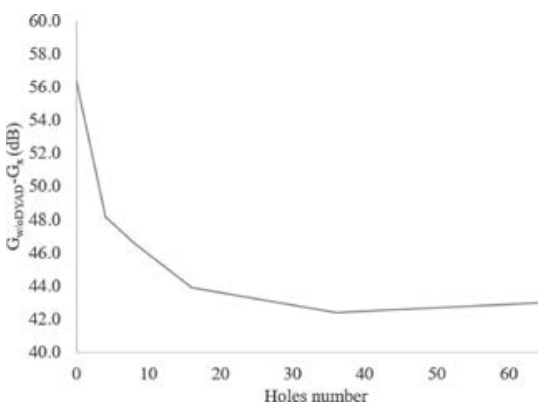

Figure 19. Receptance (dB) decrease between damped and undamped laminates.

The overall vertical displacement $U$ post-processed at the plate center allows to calculate the frequency evolution of the receptance as: 


$$
R_{\text {plate }}=\frac{U}{F_{0}}
$$

The gain can then be calculated as:

$$
G_{d B}=20 \times \log \left(\left|\frac{U}{F_{0}}\right|\right)
$$

Considering the different configurations listed in Table 6, the frequency evolutions of the receptance in $\mathrm{dB}$ obtained numerically are compared in Figure 18 for vertical excitation. It is clear that adding holes in viscoelastic layers allows decreasing significantly the receptance level of the plate.

In order to highlight more clearly the benefit of using such damping material, the receptance increase with respect to the undamped plate is plotted as a function of the holes number in Figure 19. Considering that the plates will be used as supports of the wind turbines, inserting viscoelastic $7 \%$ perforated layers with 64 holes inside the laminate seems to be the best choice when dimensioning the structure. Indeed, this choice allows to keep sufficient rigidity (only 18\% deflection gap compared to the undamped plate) altogether with around $44 \mathrm{~dB}$ of receptance level attenuation at the resonance.

\section{CONCLUSIONS}

In the study presented in this article, carbon/epoxy laminates including one viscoelastic layer were manufactured and their static and dynamic behaviors were investigated both experimentally and numerically. The main findings of this research work as follows:

- Inserting a non-perforated viscoelastic layer allowed to increase the laminate loss factor by a factor 50 as compared to undamped laminate but also decreased its stiffness by a factor 20 .

- This problem could be overcome by creating small holes inside the viscoelastic layer, which for the considered cases allowed to improve the damping performance by a factor 40 while keeping a stiffness only 5 times lower than the undamped laminate one.

- Considering experimental analysis, both damping and stiffness laminate characteristics appeared to be sensitive to the perforation surface. For the considered case, perforating only $5 \%$ of the viscoelastic surface resulted to be the best choice.

- Considering that the investigated damped laminated plates will be used in a near future as supports of two embarked wind turbines, inserting viscoelastic 7\% perforated layers with 64 holes inside the laminate seems to be the best choice when dimensioning such supports.

As a perspective of this research work, other kinds of viscoelastic materials will be tested as well as different ways to include them inside the laminate (powder, flake, holes, etc.). Regarding numerical analyses, a visco-hyperelastic law will be use to take in account viscoelastic part. Resulting numerical simulations will then have to be compared to full-scale dynamic response measurements.

\section{ACKNOWLEDGEMENTS}

This research work has been conducted with the financial support of both Energy Observer organization and FEDER - Region Pays de la Loire in the framework of CIPTAP R\&D project.

\section{REFERENCES}

Energy Observer. (2017). http://www.energy-observer. org/.

Hujare, P., \& Sahasrabudhe, A. (2014). Experimental investigation of damping performance of viscoelastic material using constrained layer damping treatment.

Liao, F., Su, A., \& Hsu, T. (1994). Vibration Damping of Interleaved Carbon Fiber-Epoxy Composite Beams. Journal of Composite Materials, 28(18).

Pan, L., \& Zhang, B. (2009). A new method for the determination of damping in cocured composite laminates with embedded viscoelastic layer. Journal of Sound and Vibration (319).

Pan, L., \& Zhang, B. (2009). Damping and Mechanical Properties of Cocured Composite Laminates with Embedded Perforate Viscoelastic Layer. Journal of Materials Science \& Technology, 25(4).

Robinson, M., \& Kosmatka, J. (2006). Improved Damping in VARTM Composite Structures using Perforated Viscoelastic Layers. Journal of Composite Materials, 40(23).

Saravanos, D., \& Chamis, C. (1991). The Effects Of Interply Damping Layers on the Dynamic Response of Composite Structures.

Soundcoat. (2018). https://soundcoat.com.

Tabiei, A. (2017, December). www.dynasplus.com.

Ungar, E., Ross, D., \& Kerwin, E. (1959). Damping Of Flexural Vibrations By Alternate Viscoelastic And Elastic Layers. Cambridge: WADC.

Wan, H., Li, Y., \& Zheng, L. (2016). Vibration and Damping Analysis of a Multilayered Composite Plate with a Viscoelastic Midlayer. Shock and Vibration, 2016.

Xu, C., Wu, M., \& Hamdaoui, M. (2016). Mixed integer multi-objective optimization of composite structures with frequency-dependent interleaved viscoelastic damping layers. Computers and Structures, 172.

Zhai, Y., \& Liang, S. (2017). Optimal lay-ups to maximize loss factor of cross-ply composite plate. (Elsevier, Ed.) Composite Structures, 168. 